Article

\title{
Energy Efficiency in the Supply Chains of the Aluminium Industry: The Cases of Five Products Made in Sweden
}

\author{
Joakim Haraldsson *(D) and Maria T. Johansson (1) \\ Division of Energy Systems, Department of Management and Engineering, Linköping University, \\ SE 58183 Linköping, Sweden; maria.johansson@liu.se \\ * Correspondence: joakim.haraldsson@liu.se; Tel.: +46-(0)-13-284786
}

Received: 23 November 2018; Accepted: 10 January 2019; Published: 15 January 2019

\begin{abstract}
Improved energy efficiency in supply chains can reduce both environmental impact and lifecycle costs, and thus becomes a competitive advantage in the work towards a sustainable global economy. Viewing the supply chain as a system provides the holistic perspective needed to avoid sub-optimal energy use. This article studies measures relating to technology and management that can increase energy efficiency in the supply chains of five aluminium products made in Sweden. Additionally, energy efficiency potentials related to the flows of material, energy, and knowledge between the actors in the supply chains are studied. Empirical data was collected using focus group interviews and one focus group per product was completed. The results show that there are several areas for potential energy efficiency improvement; for example, product design, communication and collaboration, transportation, and reduced material waste. Demands from other actors that can have direct or indirect effects on energy use in the supply chains were identified. Despite the fact that companies can save money through improved energy efficiency, demands from customers and the authorities would provide the additional incentives needed for companies to work harder to improve energy efficiency.
\end{abstract}

Keywords: energy efficiency; aluminium industry; supply chains; primary aluminium; secondary aluminium; extrusion; foundry; rolling mill; demands; focus groups

\section{Introduction}

The Brundtland report [1] defined sustainable development as " ... development that meets the needs of the present without compromising the ability of future generations to meet their own needs". Sustainability includes the three dimensions of environment, economy, and social/society [2]. These three dimensions constitute one bottom line each in the concept of the triple bottom line (TBL) of sustainable development [3]. The aim of the TBL is for companies to measure their impact on the broader economy, the environment, and the society where they operate, in addition to the traditional bottom line of financial performance (e.g., profits and shareholder value) [4]. Savitz and Weber [4] defined a sustainable company as one creating profit for its shareholders and at the same time protecting the environment and improving the lives of the people it interacts with. Savitz and Weber [4] believed that embracing sustainability is the only way to succeed in today's interdependent world.

Supply chains are systems of entities (companies and people), resources, processes, and information responsible for acquiring and transforming resources, raw materials, and components into intermediary and final products, and delivering the final products to consumers [5-7]. Goetschalckx [5] adds that a supply chain is a complex network with many divergent and convergent flows of material, information and money, which constitute linkages between different processes and 
activities. Supply chain management (SCM) is the integration of materials and information flows to and from a company [8]. SCM includes the management of a company's relationships with the companies upstream and downstream within the supply chain [8] and a strategic and systemic coordination of business functions within the company and across the companies in the supply chain [9]. Improving the long-term performance of the individual companies and the entire supply chain is the aim of SCM [9]. Green supply chain management (GSCM) incorporates environmental thinking into SCM, including product design, material selection and acquisition, transportation, packaging, and management of end-of-life products [8]. Sustainable supply chain management (SSCM) incorporates the sustainability aspects (environment, economy, and social) into the systemic coordination of key organisational business processes with the aim of improving the long-term economic performance of the individual companies and the entire supply chain [9]. SSCM needs to take a wider range of issues than purely economic ones into account and is thus likely to involve a larger part of the supply chain [10].

Several authors highlight the need to consider the entire supply chain when working with reduced energy use [11], improved energy efficiency [6], reduced environmental impact [12-14] and improved sustainability (environmental, economic, and social) $[6,15,16]$. The challenges of the triple bottom line are not simply an issue for the major transnational companies, since they will increasingly be compelled to pass the pressure onward down their supply chains [3]. Viewing the supply chain as a system provides the holistic approach needed to optimise the entire supply chain $[6,15]$. This is to avoid decisions that are optimal for an individual unit, but suboptimal for the entire system $[6,15]$. There could be opportunities for improved energy efficiency that are hidden for the individual company [6]. Moreover, energy efficiency measures with low savings for the company implementing the measure, resulting in long payback periods for the individual company, could yield large savings for the entire supply chain [6]. The supply chain perspective could also provide more potential areas for improved energy efficiency, e.g., logistics and waste management [6]. Energy efficiency in supply chains is not the sum of the individual companies but rather a wider perspective that includes the overall effects of energy efficiency improvements [6].

Centobelli et al. [17] stated that a sustainable supply chain initiative is a multifaceted concept including three parts. The first part is a managerial perspective, which is the drivers aim to produce environmental sustainability strategies involving the supply chain partners [17]. The second is an organisational perspective, which is the sustainable practices (environmental techniques and methods) shared with supply chain partners to achieve the sustainable aims [17]. The third is a technological perspective, which is the specific collaborative systems support the sustainable practices [17].

GSCM includes realising opportunities that add value to the company, e.g., cost reductions, brand differentiation and improved competitiveness, in addition to risk management [18]. The degree to which sustainable practices are integrated within the company and across the supply chain can be indicated by the GSCM performance [18].

Demands from society, customers, and the law could drive companies to improve their environmental performance, especially when the sustainable practices are more expensive in a competitive environment [19]. However, few companies "go green" only because of public pressure, but a wide range of socio-economic pressures may drive companies to become "greener", e.g., cost, consumers, shareholders, and trade organisations [20]. Walker and Preuss [21] highlight the importance of stakeholder, customer, and legislative pressure for driving the work with improved sustainability performance. Customer pressure for improvement can be passed on along the supply chain $[18,20]$. Regulatory scrutiny is costly, which persuades many companies to go beyond the compliance with current regulations to avoid costs associated with the compliance with new regulations [19]. For business and supply chain owners, cost reduction is still the primary motivation, although carbon emission reduction is recommended and sometimes enforced by law [22]. Organisations may emphasise their commitment to sustainability and the environment to appear in a positive light [20]. Protecting and enhancing the reputation of the supply chain can address social and/or environmental 
issues as strategic aspects [6]. The supply chains' leading companies are in a strong position to affect their suppliers in terms of energy issues [6].

Improved energy efficiency in supply chains has increased in importance in the research area of supply chain management because of climate change, demands for carbon footprint assessments, energy issues, and goals for energy efficiency improvements [7]. Energy efficiency and environmental sustainability in supply chains have experienced a growing research trend in recent years [17]. Even though there has been increasing interest in energy efficiency in supply chain management, previous research has primarily studied energy efficiency within individual companies [6]. In the development towards a sustainable global economy, energy efficiency is expected to become a competitive factor [7]. Improved energy efficiency in supply chains could reduce both environmental impact [7] and costs $[6,7,23]$.

Several authors have studied the reduced energy use and environmental impact of entire supply chains by focusing on supply chains in general (e.g., [6,14,19,23-27]). There are other studies that focus on supply chains in specific industries other than the aluminium industry (e.g., the food industry [28-30], the paper and steel industries [7], the automotive industry [13], the construction sector [31], the aerospace industry [18], and the clothing and furniture industries [29]).

Khoo et al. [32] presented a case study of a supply chain delivering die-cast aluminium components. Their focus was on the transportation of goods between sites, and they only considered the transportation mode and the distance travelled. Khoo et al. [32] also studied the possibility of delivering metal to a casting plant in molten form. Ferretti et al. [33] developed a mathematical model for economic and environmental evaluation of molten aluminium delivery. Milford et al. [34] studied how metal yield improvements affect the embodied energy use and $\mathrm{CO}_{2}$ emissions along the supply chains for three aluminium products. Additionally, they studied the global energy saving and $\mathrm{CO}_{2}$ emissions abatement potentials for the entire aluminium sector when all yield losses are eliminated. Haraldsson and Johansson [35] reviewed energy efficiency measures for the aluminium industry. However, their study focused on energy efficiency measures in-house for the individual companies. A literature review conducted by Centobelli et al. [17] found a research gap regarding the factors that positively or negatively affect the implementation of energy efficiency and environmental initiatives in supply chains and they requested more empirical investigations within the field of supply chain management regarding such factors.

Our paper aims at providing an understanding of which energy efficiency measures and areas for improvement that are relevant for supply chains associated with the aluminium industry. The paper will study how the companies in the aluminium industry's supply chains can work together to improve the energy efficiency of the entire supply chain. In addition, the paper will investigate demands put on the companies that can affect how the companies work with improving energy efficiency. Three research questions will be explored:

1. Are there demands from actors within and outside the supply chains that affect the energy use and work with energy efficiency?

2. What measures in regard to technology and management can improve energy efficiency in the supply chains of the aluminium industry?

3. Which are the efficiency potentials in regard to the flows of material, energy, and knowledge between the actors in the supply chains?

The demands can be on both the product and the companies within the supply chains, e.g., product properties and environmental performance of the companies. Actors outside the supply chains can, for example, be end-users of the products and the authorities.

Compared to the studies by Khoo et al. [32], Ferretti et al. [33] and Milford et al. [34], this paper takes a more holistic approach to supply chains as well as considering a wider range of case objects. Additionally, in contrast to our paper, neither Khoo et al. [32], Ferretti et al. [33] nor Milford et al. [34] used focus groups as a method. Our paper will address the relatively unexplored area of how the 
companies in the supply chains of the aluminium industry could work together on improving energy efficiency. Moreover, the paper will provide some empirical findings necessary for meeting the research gap found by Centobelli et al. [17].

\section{Methods}

The empirical data was collected through focus groups. Wibeck [36] defines the work with a focus group as "gathering a group of people who discuss a given topic with each other for a limited time" (p. 11). The methodological approach presented by Wibeck [36] provided a basis for the focus groups conducted within this paper. Focus groups were chosen as a method since they give the different actors along the supply chain the opportunity to interact. This means that all the actors along the supply chain could discuss and react to the measures and demands raised by other actors. The focus group methodology is thus better suited for studying the complexity of energy and material flows along the supply chain than individual interviews. Additionally, the focus groups provided a learning opportunity for the respondents in regard to the other companies' production processes, and how decisions affect the other companies and their energy use.

The companies were free to choose their respondents, but the respondents were supposed to have knowledge about their respective companies' production processes and energy use. The companies were given the option to send more than one respondent, e.g., an energy controller, a seller, and a purchaser. This was to ensure that respondents with competences covering all of the discussed topics attended the focus groups. The questions to be discussed at the focus groups were sent to the respondents before the focus groups. This was to give the respondents the opportunity to decide whether they wanted to bring another person from the company, or to discuss the questions with colleagues before the focus group.

The products chosen are a heat exchanger for trucks, a balcony glazing system, a component in car motors, a chassis part for trucks, and a piece of furniture. The article will focus on a part of the production of these products, which are the supply chains illustrated in Figure 1 along with the chosen system boundary. This will not give the full picture of the production of the specified products, but it will give some understanding of how the companies in the supply chains of the aluminium industry can work together on energy efficiency. The products were chosen based on recommendations from the Swedish Aluminium Association (www.svensktaluminium.se). The products, supply chains, and companies were chosen to cover all the major production processes used within the Swedish aluminium industry, and also to cover different types of applications. One focus group was conducted for each product, and each focus group contained respondents from all levels of the supply chain. The aluminium industry is here defined as companies dealing with the primary and secondary production of aluminium, rolling, and extrusion. The supply chains studied cover all large companies belonging to the Swedish aluminium industry.

The end-users of the products have been excluded, since the purpose is to study the production of aluminium products. However, aspects of the end-users' energy use and their demands on the products appeared indirectly in the discussions. Demands from aluminium recyclers were included through their participation in one of the focus groups and through reflections from the other companies. In the furniture focus group, a respondent from a primary aluminium producer was supposed to be present but could not attend the focus group in person. However, they supplied their views on the questions beforehand, and these were raised during the focus group discussion by the moderator. Additionally, as for all focus groups, there were opportunities to ask supplementary questions after the focus group discussion was finished. In the production of the truck chassis part, no primary or secondary aluminium producer was involved. This is because the billets are produced in a melting plant owned by the chassis part producer using waste material from the production of the chassis part and other components that the profile extruder produces.

The discussions in the focus groups focused on what the companies can do together to improve energy efficiency in the supply chain and on the potential for improved energy efficiency. 
Additionally, demands from different actors and how these affect energy use were discussed. Questions revolving around these aspects were formulated and sent to the respondents before the focus groups. These questions were general in their nature (not focussing on pre-determined efficiency measures or demands) and provided a basis for the discussions during the focus groups. However, the discussions were not strictly guided by the pre-formulated questions. At the beginning of each focus group, the moderator gave an introduction and then asked the initial question: "What can the companies do to make the energy use of the entire supply chain as efficient as possible?" From that point on, the respondents were free in their discussions around the three themes (how the companies can work with energy efficiency, energy efficiency potentials, and demands) and had the opportunity to ask each other questions. The moderator guided the discussions to some extent to make sure that all three themes were discussed to a sufficient extent and to pick up loose threads in the discussions. There was no direct competition between the companies to impede the discussions, and the discussions were characterised by openness between the respondents.

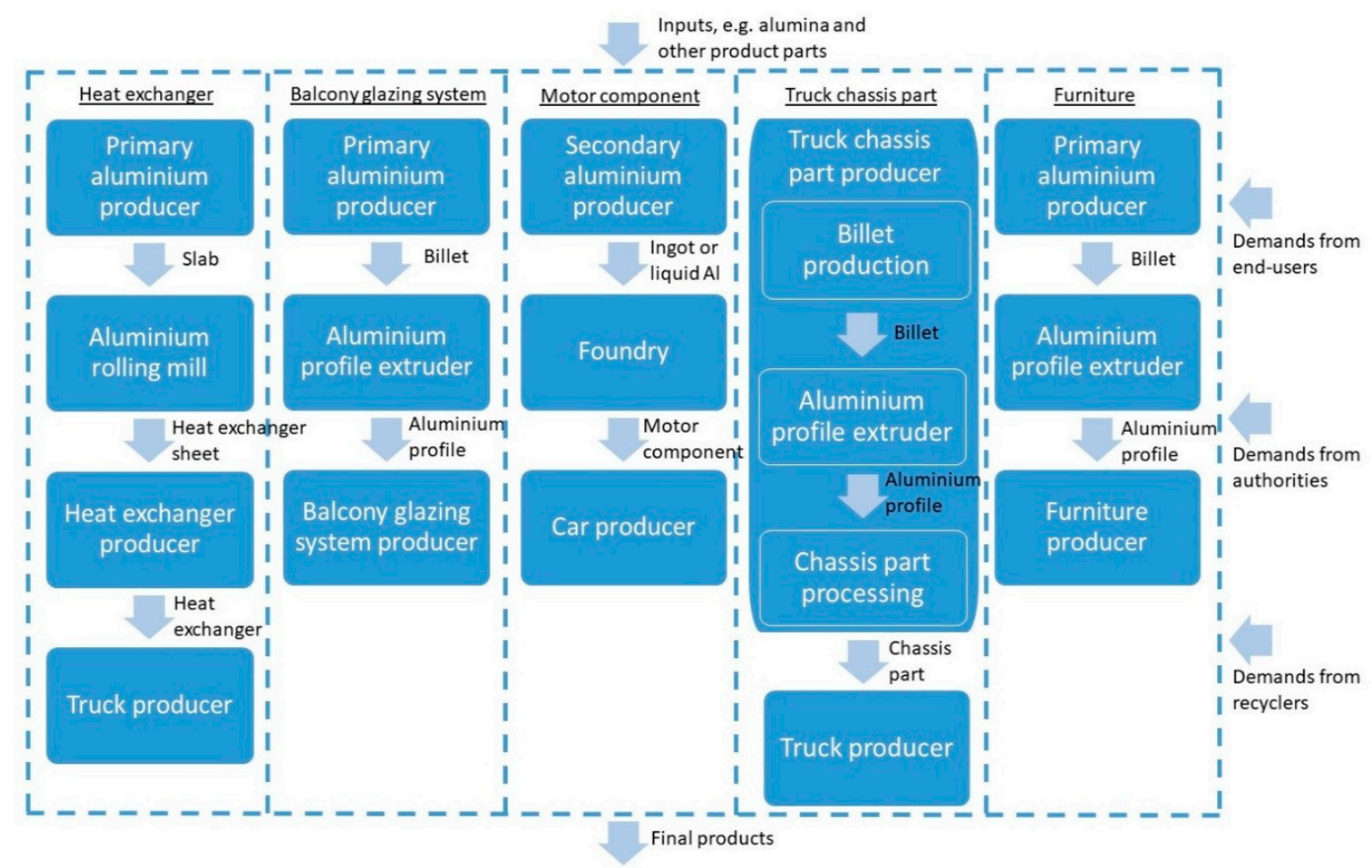

Figure 1. The supply chains studied in the article and the chosen system boundary.

The focus group discussions were audio recorded, transcribed in full and coded. Saldaña [37] defines a code as "a word or short phrase that symbolically assigns a summative, salient, essence-capturing, and/or evocative attribute for a portion of language-based or visual data". The "main" codes used were "measure" (short for "energy efficiency measure"), "demand", and "potential", but more specific codes were developed based on the focus group material. The main codes were decided on before the coding started, while the specific codes were developed during the coding. For the energy efficiency measures, a name or short description of the measures was added to the codes. For the demands, the specific codes were based on the type of demand or the actor making the demand. When it comes to potentials, the specific codes were based on the name or description of the measure that the potential regards or includes the word "general" if the potential regards the entire supply chain. In addition to the three "main" codes, other codes were developed for parts of the material that were not directly related to the aim and research questions of the article, but that may still be worth including in the article. 
The starting point for the analysis was to group together all parts of the focus group material that dealt with the same aspect, e.g., the same measure or demand. A summarising description of each aspect was then formulated. Each focus group was first summarised separately, so that the text could be sent to the respondents for verification that the interpretation was correct and so that they could add further information if they so desired. The material from the different focus groups was then combined. This is in accordance with the descriptive analysis approach described by Wibeck [36], where a summative description of the data is provided, along with some illustrative examples. The division of the results and analysis chapter, and the associated phrasing of the headings for the sub-sections, are based on the material from the focus groups, and not on any energy efficiency measures or demands determined prior to the focus groups.

Table 1 shows the length of recording and number of company respondents for each of the focus groups. The lengths of recordings for the focus groups dealing with the motor component and the truck chassis part include one break each of about 8-9 $\mathrm{min}$. The number of focus groups is sufficient when clear patterns are identified and additional focus groups would only give repetitious information, i.e., a theoretical saturation is achieved [38]. Only three or four focus groups might be needed for simple research questions [38]. As will be shown in Section 3.14, there are overlaps between what was discussed in the different focus groups. This means that five focus groups were considered sufficient to meet the aim and answer the research questions of this study.

Table 1. Length of recording and number of company respondents for each of the focus groups.

\begin{tabular}{ccc}
\hline Focus Group & Length of Recording & Number of Company Respondents * \\
\hline Heat exchanger & $1 \mathrm{~h} 36 \mathrm{~min}$ & 4 \\
Balcony glazing system & $1 \mathrm{~h} 31 \mathrm{~min}$ & 3 \\
Motor component & $2 \mathrm{~h} 10 \mathrm{~min}$ & 7 \\
Truck chassis part & $2 \mathrm{~h} 14 \mathrm{~min}$ & 4 \\
Furniture & $1 \mathrm{~h} 38 \mathrm{~min}$ & 4 \\
\hline \multicolumn{2}{c}{${ }^{*}$ Excluding the two researchers participating in all five focus groups. }
\end{tabular}

Krueger and Casey [39] argued that it is better to invite fewer people to each focus group if the aim is to understand an issue, if the topic is complex, if the participants are experienced in or passionate about the topic, or if there are many questions to be covered during the focus group. The topic in our article is complex in the sense that there might exist many demands put on the companies, and many energy efficiency measures that could be conducted. There are thus many questions to be covered. The aim is to understand how the companies can work together on energy efficiency and what are the demands that affect the work with energy efficiency. The respondents are experienced in the topic since they work with energy issues or customer contact at their respective companies. This means that a fewer number of participants in each focus group is favourable in this study.

\section{Results and Analysis}

This chapter presents the results from the focus groups and our analysis. The first section presents the different demands raised during the focus groups, which are divided into: Economic demands, demands regarding product quality and performance, and demands regarding environmental performance. The subsequent sections describe the energy efficiency measures raised during the focus groups. Each of these sections describes a specific energy efficiency measure or an area for potential energy efficiency improvements that includes several measures. The next section discusses energy efficiency potentials in the supply chains. The final section provides an analysis of the different measures in relation to the different supply chains studied.

The length of each section/topic does not necessarily reflect the importance of each section/topic. Some energy efficiency measures are more complex than others or include different aspects and thus need a more extended description. Additionally, some topics were relevant and discussed in several of the focus groups, resulting in more data material. 


\subsection{Demands from Actors Within and Outside the Supply Chains}

Each actor within the supply chains is subject to different demands from other actors within the supply chains, as well as actors outside the supply chains. The focus groups discussed demands related to economics, product quality and performance, and the environment, which indirectly affect energy efficiency. They also discussed governmental demands that directly address energy efficiency.

\subsubsection{Economics}

Cost-effective production implies that suppliers can offer a lower price to their customers, which is a competitive advantage. Energy is a cost and improving energy efficiency will reduce production costs. During the focus group discussions, price demands from customers were considered to be an important motivation for improving energy efficiency. Even though there has been increased interest in energy and environmental issues over the past ten years, other aspects, such as product properties, quality and price, are still more important. The companies are not prepared to pay a higher product price as a result of one company conducting a measure aimed at reducing energy use or environmental impact. Therefore, when working with energy efficiency, the largest driving force is monetary savings. Economic policy instruments would be needed to make the energy and environmental aspects more interesting to these companies.

The actors in the heat exchanger supply chain are affected by demands from the buyers of the trucks in which the heat exchanger is mounted. The end-users make demands in terms of price, operating costs, and performance of the trucks. The truck producer focuses on making the trucks as fuel efficient as possible but has little knowledge of how this affects energy efficiency in the production of the heat exchanger upstream in the supply chain. However, information provided by the heat exchanger producer about how much different energy sources account for within the total cost of the heat exchanger could offer a basis for customers to make demands about the amount and type of energy used. Although the soldering process is quite energy intensive, energy constitutes a very small part of the total cost for the heat exchanger producer. This implies that there could be less incentive for the heat exchanger producer to identify possible areas for energy efficiency. However, the situation is almost the reverse for the primary aluminium producer, since about $30 \%$ of all their production costs are only for electricity.

The companies that recycle aluminium do not make any demands about the design of the products or the alloys used in order to be able to recycle them. However, they have demands relating to the sorting of the scrap. This is also shown in the price that the recycling companies offer for scrap; the better the scrap is sorted, the higher the price. The heat exchanger producer has discussions with the recycling company about how they should handle scrap. In summary, the companies want to minimise the amount of scrap and maximise the value of the scrap that is produced.

\subsubsection{Product Quality and Performance}

During the focus group discussions, product quality and performance were highlighted as among the most important demands from customers. The balcony glazing system producer makes demands on the surface finish, which has a large effect on the amount of internally generated scrap at the profile extruder. In the focus group for the chassis part, it was mentioned that the end-user demands a high payload factor of the truck, which indirectly makes demands on achieving a low weight of the truck construction. In the focus groups for the heat exchanger, motor component and chassis part, it was stated that the end-users have demands on the energy efficiency of the truck or car they buy.

The truck producer makes demands on the performance and lifetime of the heat exchanger delivered to them. They also want the heat exchanger to be designed so that it is easy to mount in the truck and easy to maintain when in operation, as well as being small and lightweight. However, the truck producer stated that the buyers of the truck make demands on the engine's performance, lifetime, and maintenance rather than direct demands on the heat exchanger. The respondents stated 
that the lifetime of the heat exchanger attracts the most attention at the design stage. The lifetime needs to be at least as long as the customer requires, and this determines the truck producer's specifications for the material strength. A heat exchanger is required to maintain a high engine performance and the fuel demand will increase if the heat exchanger does not work well. The important aspect is how the heat exchanger interacts with the engine, rather than how much heat it should transfer or what capacity it should have. The heat exchanger producer and the truck producer stated that the performance of the heat exchanger has reached a near optimum level and little potential is left for further improvements.

Demands on the material strength were discussed in all focus groups. The products need to withstand a certain level of force and stress without bending, breaking, or cracking. During the focus group discussion for the balcony glazing system it was highlighted that the metal needs to resist weather-imposed wear. Some of the demands on material strength come from the law or authorities. For example, the balcony glazing system producer is required to conduct impact tests on the balcony railing, according to the building regulations formulated by the Swedish National Board of Housing, Building and Planning. The profile extruder checks the hardness of the profiles in every batch or every delivery to ensure that the material strength is within the specified boundaries. The profile extruder stated that the demands on material strength result in large amounts of scrap in their production, because of safety margins. The scrap from a company is typically remelted within the company or sent to another company for remelting, which increases the total energy demand compared to a situation in which all the metal is used directly in a product without any waste. For the balcony glazing system, the amount of scrap is one of the largest factors affecting energy use. For the chassis part, the demands on material strength have led to the need to lengthen the time of the ageing cycle in the furnace, which in turn increases energy use.

\subsubsection{Environment}

Demands from customers in relation to energy are often directed to the use of green energy rather than improved energy efficiency. In the heat exchanger focus group, the respondent from the truck producer stated that the truck buyers do not ask for information about material and energy use in producing the trucks or transportation distances of the trucks to the buyers. The primary aluminium producer stated that:

"It appears more common that industrial customers, as well as society as a whole, demand a green product, within quotation marks. The demand can be phrased in different ways, for example that it should be renewable electricity. It appears that you take it one step further when demanding energy-efficient production. In a way, it appears easier to make the first demand. Demanding that the aluminium should be produced using hydropower or similar appears easier than demanding a certain efficiency in the production process. To be able to make demands about energy efficiency, the ones making the demands need deeper knowledge."

Moreover, the primary aluminium producer has so far had no demands from their customers for so-called green aluminium. The heat exchanger producer does not receive any demands from their customers about the type of electricity either, just that it should be cheap. Both the primary aluminium producer and the heat exchanger producer stated that if they were offered a lower electricity price, they would not hesitate to take it, even if it is "dirtier" electricity, such as coal power, since this would save quite a lot of money in the end:

"The process is not less energy efficient because of the use of coal power. It is just as efficient, but the environmental impact is not as good. It depends on what you want to achieve."

Several of the companies in the supply chains have a certified environmental management system according to ISO14001, but they have not experienced any demands from customers to have a certified energy management system according to ISO50001. However, some of the companies handled the 
monitoring of energy through their environmental management system. The primary aluminium producer stated that it would be interesting to introduce an energy management system even without external demands from the authorities or customers. This is because there is an economic gain in controlling, monitoring, and improving energy use in an organised way. The primary aluminium producer added that demands from customers and the authorities could provide additional incentives for implementing an energy management system. The primary aluminium producer believed that it would be easier for the customer to demand that the supplier has an energy management system instead of demanding a certain efficiency in their process.

The profile extruder in the supply chain of the balcony glazing system has an energy management system certified according to ISO50001, since the company participated in the Swedish Energy Agency's programme for improved energy efficiency in energy-intensive industries. One demand on participants was to implement an energy management system certified according to ISO50001. Moreover, some of their customers ask questions about energy use and the potential for improvement. Additionally, one of their other customers wanted to know the amount of emissions per kilogram of aluminium profile.

The furniture producer does not demand that their suppliers have any ISO certifications. They believe that it is good if their suppliers have ISO certifications and the certifications, in many cases, can work as a follow-up. However, they believe that their suppliers' values and corporate cultures are more important in the work with energy efficiency and sustainability than having certifications.

There is a law demanding that large enterprises conduct an energy audit (https: / www.iea.org/ policiesandmeasures/pams/sweden/name-167642-en.php), which affects the large companies in the supply chains. This may also lead to customers starting to demand extracts from the energy audit report to see where the energy is used in the various processes.

Demands for green energy or for an energy management system to ensure active work with energy efficiency at the company need to be made by either the customers or the law. In this way, there will be additional incentives for the companies to engage with the issue, despite the fact that they can save money through energy efficiency. However, the profile extruder in the balcony glazing system focus group believed that more of their customers would become interested in discussing energy issues in the future. Moreover, in the furniture focus group, both the profile extruder and the furniture producer receive demands from customers about using renewable energy in their production. They also pointed out that end-users have considerable power today and that their demands will surely increase over time. The sustainability aspect is important today and will become increasingly important in the future.

The secondary aluminium producer mentioned that laws on emissions can affect energy efficiency. They are obliged to burn their exhaust gases because of the bad smell, since they are located centrally in an urban area. This requires additional fuel to heat the gases up to $800-850{ }^{\circ} \mathrm{C}$. There are also legislative demands that trucks must comply with regarding exhaust emissions. The performance of the truck's heat exchanger will have a direct impact on exhaust emissions and thus on the ability to comply with the legal requirements.

None of the supply chains had experienced demands from end-users on energy use in production. End-user demands are instead associated with the material itself; for example, that there are no hazardous substances such as heavy metals and toxins. However, improved energy efficiency in the aluminium industry was emphasised as important for strengthening the aluminium's competitiveness towards other materials. Thus, it is important to put pressure on companies within the aluminium industry to work more with energy efficiency. It would be good if the pressure comes both from the aluminium industry's customers, such as the furniture producer, and from within the aluminium industry itself, e.g., the profile extruder putting pressure on the billet suppliers.

\subsection{Product Design}

A topic discussed in all the focus groups was product design. Product design work has the greatest importance for energy efficiency, since it is during this phase that the foundations for the 
subsequent work are laid. One respondent stated that as much as 80 to $90 \%$ of the cost of producing a product part can be affected during the design phase.

\subsubsection{Collaboration on Product Design}

When developing the product design, collaboration between the producers of the final products and their suppliers would be beneficial, especially when the producers of the final products are not accustomed to working with aluminium. The respondents considered this vital in order to avoid costly modifications later on during the production phase. The point was raised during the motor component focus group discussion that communication between all the companies in the supply chain during the design phase, where all the companies have the opportunity to give feedback and make suggestions on the product design, would be beneficial. The suppliers could propose changes to the design, allowing for easier and more efficient production, while still meeting the product specifications and without significantly affecting the final product's functions. These changes could lead to reductions in material use, material waste, and energy use. However, in some cases, there are demands from the market that make it difficult to implement certain changes to the design, even though this would save money and energy.

A collaboration starting early in the development process commonly involves much larger changes to the first design draft. However, this collaboration would mean that one specific supplier is involved in the design phase, which implies that the supplier claims the right to the business deal. On the other hand, the producer of the final product wants to send the design to several suppliers to encourage competition during procurement. To avoid this conflict, the supplier that helped with the design could be paid for the development work if they is not awarded the business deal.

Moreover, it is always possible to rationalise and make improvements to a design after the production start, which could save money, time, and energy during production. A collaboration to improve the design of an existing product part would be beneficial, since the design could be improved incrementally. It is common to add some extra material or extra details during design development to improve it. However, there might be limitations on the size and type of the changes that can be made. This could be because other product parts will be affected by the changes, as well as costs associated with changing the design, e.g., costs for impact tests.

\subsubsection{Design for Increased Recyclability}

A product should be designed in a way that facilitates the recycling of different materials at the end of its lifetime. One possibility is to facilitate the disassembly of the product so that the different materials can be separated. Another possibility would be to design the product in a single material. This is important since using recycled aluminium from post-consumer scrap requires much less energy than producing the same amount of aluminium from primary sources. The possibility of recycling more of the aluminium in a product was valued as more important than the actual amount of recycled aluminium used in the product, due to the high second-hand value of aluminium scrap. The furniture producer might even be willing to pay the end-users a small amount of money to bring the products back at the end of their life in order to achieve a closed loop in the recycling of materials.

Anodised aluminium is better in regard to recyclability than powder-coated aluminium, which is shown in the second-hand value. In most cases, the buyers of the balcony glazing system are more interested in the colour of the aluminium details than the fact that anodised aluminium has a higher second-hand value. Stripping off the powder coating to facilitate the recycling of the aluminium is not very energy intensive, but it still constitutes a cost.

\subsubsection{Product Weight and Material Use}

For the products used in vehicles (heat exchanger, motor component, and chassis part), the product weight is an important aspect. This is to reduce the overall weight of the vehicle and thus its fuel demand. For trucks, it is also a means of increasing the payload and compensating for the increased 
weight due to having more conveniences in the driver's cabin. The work on reducing the weight could lead to a reduction in the amount of aluminium bought, which leads to reduced costs as well as potential energy savings upstream in the supply chain. The product weight can be affected by the material choice, e.g., using aluminium instead of steel, and designing a component to incorporate several functions instead of having one component for every function.

Developing new heat exchanger technology or using thinner metal sheets could reduce the weight of the heat exchanger. However, thinner sheets would require the rolling mill to develop a stronger alloy and there is a limit to how thin the sheets can be while still meeting the product specification from the truck producer. If the heat exchanger becomes too sensitive, the truck producer will need to put something in front of it to protect it, which will require extra material. Additionally, for every thickness reduction, the sheets become harder to process.

The furniture producer wants to use as small an amount of material in its products as possible, for example by using hollow constructions. Another possibility is to design the aluminium profile in a way that eliminates some of the subsequent processing with associated material waste.

\subsubsection{Choice of Alloy}

In some cases, the producer of the final product specifies exactly which alloy or which alloy type they want, while others leave it entirely to their suppliers to choose an alloy based on the product specification. Choosing an alloy that is easier to produce and process, while still meeting the product specification, could reduce the energy demand and cost of producing the product as well as increasing productivity. Another aspect to consider is choosing an alloy that reduces wear on the production tools and eases the machining of the metal and the handling of metal chips from processing. Therefore, it would be beneficial to leave the decision to the company that has the knowledge required to make a sound decision, or at least to let them have their say in the decision-making process.

In order to increase the use of secondary aluminium, it would be better to use a standard alloy than to develop a new special alloy, because there is more post-consumer scrap available for a standard alloy. Additionally, scrap should be sorted based on alloy to allow for efficient production of secondary aluminium, with a minimal addition of alloying elements or pure aluminium in the melting plant. A special alloy would be sorted into a separate pile, which involves extra work.

\subsubsection{Design Aspects in Specific Supply Chains}

A number of holes are needed on the truck chassis part, which are used when mounting it onto the truck. The placement of the holes has a larger impact on the strength of the chassis part than the alloy does, and the best option would be to have no holes at all. The truck producer has four variants of the chassis part, depending on the truck model. Choosing a variant with fewer holes increases productivity and saves energy in production, due to a lower need for processing.

Surface treatment was discussed during the chassis part focus group discussion. The truck producer was concerned about corrosion and how this would affect the collision properties of the chassis part. The truck producer had earlier specified that the chassis part should have a surface treatment. However, the chassis part producer highlighted that $80 \%$ of the truck industry does not use a surface treatment and since the chassis part is not a visible part of the truck, it would be possible to skip it. Due to this advice, the truck producer took a risk quite early in the development process and decided to exclude the surface treatment. Corrosion tests in a laboratory environment conducted by the truck producer on both the chassis part and an entire truck showed that the chassis part could withstand corrosion satisfactorily even without surface treatment. The truck producer also conducted impact tests on chassis parts that had first been subject to corrosion tests, which showed no significant effect on the collision properties. There have been trucks in operation for many years without any problems with corrosion of the chassis part. The respondent from the truck producer had not heard of any complaints about corrosion from the truck buyers. Both energy and money were saved by eliminating the surface treatment. 
During the development of a furniture product, there are discussions about the packaging solution. The package should be flat, as small as possible, and have as little empty space as possible. This is to allow for more transported goods on every truck, which reduces the energy use and cost of transportation. The packaging should also be designed so that the end-user can take the product home on the bus, for example, instead of taking the car. The packaging solution can have an effect on the product design in order to allow for smaller packaging without affecting the functionality or production of the product. Additionally, the requirement to fit the product into a flat package entails the need to think about easy disassembly right from the start.

A topic discussed during the motor component focus group was the car's performance. The car producer stated that if the end-user did not demand as much horsepower, it would be easier to make the car more energy efficient. Furthermore, the car producer's work with improving the energy efficiency of the motor has led to larger stresses on the cylinder head, which puts higher demands on the material properties. This has led to a change from secondary to primary aluminium alloys on the cylinder head. Even though the car becomes more energy efficient, the production of some product parts requires more energy, due to the use of primary aluminium.

\subsection{Communication and Collaboration}

Communication and collaboration between companies were raised as important for achieving improved energy efficiency in the supply chains studied. This was discussed and agreed upon in all five focus groups. The more the energy issues are discussed, the more they become a self-evident part of all the work the companies do. However, it is common today that the energy aspect enters only indirectly into discussions, e.g., when discussing how to eliminate the wasteful use of resources and how to reduce material use.

During the motor component focus group discussion, the secondary aluminium producer requested more dialogue with the car producer. This implies that increased communication between all the companies in the supply chain, and not only between customer and supplier, would be beneficial. Each company commonly has specific contact persons at the other companies, e.g., sales representatives and product developers. However, a wider cross-company exchange could have large benefits. It was suggested that a contact in the production department at the other companies would be of interest. The production departments could help the other companies to solve problems that the sales representatives and product developers do not know about and enable discussions about a wider range of questions than is possible today.

One aspect of the collaboration is to increase knowledge about the other companies' production processes and correlated energy use. The more the companies know about each other's processes, the more they can work together to improve energy efficiency in the entire supply chain. The car producer stated that:

“... it is clear that you benefit from a collaboration when improving your own process. If you know what the end-user wants and when you see how the product part is used, then that can make it easier when improving your own process."

Communicating major modifications in such areas as product design to the other companies is an important way to avoid the sub-optimisation of energy use in the supply chain. Such modifications may affect the other companies' investment decisions, which could relate to production machines with a long economic lifetime. This means that if a suboptimal decision is made in the investment process, there is a risk that the energy use could be unnecessarily high over a long time period due to the long lifetime of production machines. Communicating accurate expectations of product quality and function can reduce the amount of unnecessary product disposal and material waste. This was brought up in the balcony glazing system focus group when discussing the demands on the surface appearance of the aluminium profiles. Sometimes, profiles are scrapped because of surface defects that would not have affected the appearance of the finished balcony glazing system. 
During the motor component focus group discussion it was mentioned that when starting production on a new product part, the companies have discussions on where the production machines are best suited. The aim is to reduce the risk that a new production machine is bought instead of optimising the use of machines that have already been installed. The degree of utilisation and the location of the machines have effects on energy use and the environment. Normally, the companies do not discuss energy directly, but they do so indirectly when considering parameters such as reduced car weight (leading to lower fuel demand) and reduced processing time (leading to lower energy use in production). However, it is worth raising the energy aspect during the discussions and thinking about which solution would be most efficient.

More collaborative work and regular meetings were considered beneficial for improving energy efficiency in the supply chains. However, during the balcony glazing system focus group discussion, the primary aluminium producer stated that it would be hard for the companies to take part in each other's energy efficiency projects, since the companies are too different. On the other hand, during the furniture focus group, it was highlighted that communication between companies about energy issues could be significantly improved.

\subsection{Transportation}

A topic that was discussed in all five focus groups was transportation. One issue is to optimise the transportation by filling each load with as many products as possible. This can be facilitated by designing the product in a way that makes it easier to fit as many products in each load as possible and by transporting different products together. An increased maximum allowed truck weight would reduce the fuel demand per transported tonne of product. The payload could also be increased by reducing the weight of the truck's construction and the support structures such as pallets and racks.

The transportation distance could be reduced by having direct flows for transported goods instead of sending the goods via intermediaries. However, the motor component is cast at the foundry, then transported to another site for processing, and then further transported to the car producer. This is optimal from a transportation distance perspective, since the processing site is located between the foundry and the car producer.

Another way to reduce the transportation distance is by sourcing input materials and semi-finished products locally. Another benefit of obtaining the input materials and semi-finished products from Sweden compared to, for example, Germany, is that Sweden has a higher maximum permitted truck weight than Germany.

Optimising transportation leads to reductions in energy use, environmental impact, and cost. However, there are other trends that lead to an increased transportation intensity. Examples are demands for reduced storage and achieving a high level of lean manufacturing, which leads to lower stockholding. The choice of transportation mode also has an effect on energy use, environmental impact, and cost.

\subsection{Reduced Material Waste}

The focus groups for the heat exchanger, the balcony glazing system, and the chassis part discussed the importance of reducing material waste in order to improve energy efficiency. It is important that the products they buy, e.g., slabs and sheets, have the right dimensions in order to avoid material waste and unnecessary machining, with its associated energy use. However, the entire supply chain must be considered. As an example, the heat exchanger producer needs sheets with a width of just under one metre to produce the heat exchanger, which is not a standard width provided by the rolling mill. The sheet widths offered by the rolling mill are limited in number and chosen based on the most common customer demands, due to reasons of profitability. This implies that a certain amount of metal needs to be cut off and wasted. Another limiting factor is the plating line at the rolling mill, which is constructed to process the standard dimensions. Moreover, producing smaller sheets at the rolling mill requires narrower slabs from the primary aluminium producer, which would reduce their 
productivity (in tonnes), since narrower slabs take just as long to cast as wider ones. However, the heat exchanger producer stated that, despite the increased costs for the companies upstream in the supply chain, it would still be beneficial to use narrower sheets because of the savings in their processes. Another solution to the sheet width problem that was suggested during the focus group discussion is to change how the sheets are fed into the machines at the heat exchanger producer's site by rotating them by $90^{\circ}$. However, this would require an investment in larger machines and consequently a larger production area would be needed, for which there is no space at the moment. There may also be an increased need to transport the sheets using robots within the production process, which increases the production cycle time.

The balcony glazing system producer stated that they need to cut off the ends of the profiles, primarily when using anodised profiles. Anodising is an electrolytic process that needs a contact between the profile and the electrolyte, which leaves marks from the clamps that hold the profiles. Due to customer demand for an unblemished surface finish, the parts of the profile showing such marks or scratches need to be cut off. A solution would be to position the clamps in a place where the marks are not visible to the customer. However, in this case, all parts of the outside of the profiles are visible to the customer. If the clamps were positioned on the profiles' inside, this would require manual intervention on every profile and thus increase processing time. It is worth reviewing the surface finish demands and considering less strict demands for surfaces that are not visible.

\subsection{Closed-Loop Remelting}

There is a difference between recycling and remelting. Recycling is the recovery of metal from end-of-life products, while remelting is recovery of material waste from production. Closed-loop remelting implies that the wasted material is remelted within the company or sent back to the supplier for remelting, and not sold on the open scrap market. These material flows are typically clean metal of specified alloys.

Closed-loop remelting was discussed in the focus groups for the chassis part and the motor component. It was stated in both focus groups that closed-loop remelting would be better from an energy perspective than sending the scrap to a recycler. The chassis part producer tries to remelt as much of their own scrap in their billet production as possible, because then they can retrieve the full scrap value themselves. The company can also handle scrap containing small amounts of other materials besides aluminium. The foundry can remelt product parts that are made purely from one aluminium alloy and are free from other materials. However, the scrap volume needs to be large enough to make it feasible. Another barrier could be if there is an existing contract with a recycling company. The respondents in the furniture focus group thought that cut-off metal pieces should be either reused directly in a product or remelted.

\subsection{Secondary Aluminium or Remelted Process Scrap Instead of Primary Aluminium}

Both the production of secondary aluminium and remelting of process scrap require about $95 \%$ less energy than producing primary aluminium. There is a lot to be gained from a general sustainability perspective by using secondary aluminium, e.g., reduced environmental impact. However, a current challenge is that the long lifetime of aluminium products means the available post-consumer scrap cannot meet the high demand for secondary aluminium.

Secondary aluminium may contain different impurities and unwanted alloying elements, which vary with the scrap used. This may affect the properties of the metal, and secondary aluminium is not always able to achieve $100 \%$ of the demands in the product specification. Reviewing the product specifications, the demands on material properties, and how much these could be allowed to deviate could allow for the use of secondary instead of primary aluminium alloys.

Despite any impurities and unwanted alloying elements in the scrap, it is possible to produce secondary aluminium of high quality since the metal quality depends primarily on the melting plant 
and the knowledge of the supplier. The metal quality can be improved by adjusting the process based on the scrap used.

Scrap is commonly sorted based on alloy to allow for efficient production with a minimal addition of alloying elements or pure aluminium in the melting plant. Improving the sorting at the companies where scrap occurs or at the companies collecting and handling scrap would thus be beneficial. This would increase the added value of the scrap. Additionally, cleaner scrap could reduce the amount of burning from organic compounds in the furnace as well as reducing the amount of slag produced in the furnace.

\subsection{More Research}

In the balcony glazing system focus group, the respondents discussed the importance of research to achieve improved energy efficiency. They said that there has been limited research on aluminium, in Sweden and worldwide, when compared to steel, for example. There is a lot more to be done in aluminium research, especially when it comes to energy issues. The profile extruder added that there are no significant differences in how aluminium profiles are produced globally and they have not recently heard of any significant inventions that would revolutionise production. However, they have a kind of research collaboration with one of their billet suppliers, whereby the profile extruder can point out problems with the billet and the supplier can investigate the problem.

\subsection{Delivery of Molten Aluminium}

A topic discussed during the motor component focus group was the possibility of delivering aluminium in molten form from the secondary aluminium producer to the foundry. Special trucks equipped with thermally insulated transport crucibles are used to transport the molten aluminium. The foundry demands that the metal has a certain temperature and the secondary aluminium producer heats it enough to ensure that it has the right temperature when arriving at the foundry after accounting for thermal losses during transportation. The crucibles also need to be preheated before filling. The delivered metal can either be poured into a holding furnace for later use or be used directly in production, eliminating the need for interim storage. Good planning is required to deliver the metal to the foundry just in time to avoid unnecessary heating at their site and to reduce the time spent in the preheating station at the secondary aluminium producer's site.

When looking at the energy use for the entire supply chain, delivering aluminium in molten form could provide energy savings. There is also a potential environmental benefit, e.g., $\mathrm{CO}_{2}$ emissions could be reduced due to the elimination of remelting at the foundry. The metal quality when delivering it in molten form is at least as good as when remelting ingots. However, the transportation cost is higher compared to the transportation of ingots.

\subsection{Assisting Energy Audits at Suppliers}

The furniture producer is conducting energy audits at some of their suppliers' sites to map energy use and find measures for improved energy efficiency. This service is only offered to companies that lack their own resources to conduct energy audits. The furniture producer pays half the cost of the audit and the supplier the other half, with the agreement that the supplier can take all the savings in the first year and from the second year it must have an effect on the price. The furniture producer follows up these energy audits continuously.

\subsection{Mapping Energy Use throughout the Supply Chain}

In the motor component focus group, it was stated that there is a lack of understanding about how much energy is used in different parts of the supply chain. A starting point would be to map energy use throughout the supply chain and visualise it for the companies. This could provide a foundation for discussions on where the biggest efforts for improved energy efficiency should be directed. The respondent from the car producer believed it would be interesting to see how large a 
proportion of the total energy use of the entire supply chain relates to transportation, since they buy car parts from both within Sweden and abroad.

\subsection{Sustainability Classification of Suppliers and Products}

The furniture focus group discussed environmental classification as a way to increase energy efficiency in the supply chain. The furniture producer has a system whereby they classify and score all their suppliers on an annual basis on three aspects: Energy, water and waste. The energy aspects include how efficiently the energy is used and which energy carriers are used. Energy audit is an important tool in this classification work. The suppliers receive a score depending on how far they have come in their work with the three aspects and how much additional potential they have. These scores, together with the product price, determine which suppliers the furniture producer chooses. The profile extruder believed that the classification system is a good way to drive sustainability issues forward, since it is clear what is being measured. It could have additional positive effects if connected to business decisions and communicated to end-users.

The furniture producer also classifies each of their products according to the same system. When developing a new product, the furniture producer has the ambition that it should have at least a $20 \%$ better score than the existing product. Reduced energy demand is important for achieving an improved score. The score evaluation is conducted when the product prototype is ready. If the prototype does not achieve a certain score, then the product will not become available in stores.

\subsection{Potential for Energy Efficiency Improvements}

During the motor component focus group discussion, it was agreed that the greatest potential for energy efficiency would probably be within each individual company and not so much between the companies in the supply chain. It is within a company that the work with energy efficiency is usually conducted, but it would be interesting to look at the entire supply chain to gain some understanding of the broader picture. During the focus group discussion, the respondents started discussing energy efficiency measures within the individual companies on many occasions and discussed their respective goals for energy use per produced unit. This might support the statement that the greatest potential for energy efficiency is within the individual companies.

Similarly, during the balcony glazing system focus group discussion, the issue was raised that the primary aluminium producer has a potential internally for energy efficiency, which does not directly affect their customers. The primary aluminium producer estimated that $95 \%$ of the potential for improved energy efficiency would be within their own company, while only $5 \%$ would come from working together with other companies. However, the balcony glazing system producer believed that there is not much that can be done in their production from an energy efficiency perspective, since their processes are so basic.

\subsection{Demands and Measures Discussed in the Different Focus Groups}

Table 2 shows in which focus groups the different demands were discussed. It is worth noting that even though a demand was not discussed in a certain focus group, it could still be relevant for that supply chain. For example, the importance of the economic aspect was discussed in all focus groups except the one for the balcony glazing system. The economic aspect would most likely be important for the balcony glazing system supply chain as well, since most companies are driven by the generation of economic profits. In all five focus groups, it was stated that there are no explicit demands from end-users for energy-efficient production. It is worth noting that the main topics "economics" and "product quality and performance" have marks on both the main topics themselves and the more specific aspects in Table 2, while the main topic "environment" only have marks on the specific aspects. This is because the focus group discussions on economics and product quality and performance revolved around both general and specific aspects of the topics. For the environmental 
demands, the focus group discussions revolved more around specific aspects and were not as much about general aspects.

Table 2. The demands discussed in the different focus groups. Note that the table only shows whether the demands were discussed and not whether it actually occurs in the supply chains.

\begin{tabular}{|c|c|c|c|c|c|}
\hline \multirow[b]{2}{*}{ Demand } & \multicolumn{5}{|c|}{ Focus Group } \\
\hline & Heat Exchanger & $\begin{array}{l}\text { Balcony Glazing } \\
\text { System }\end{array}$ & Motor Component & Truck Chassis Part & Furniture \\
\hline Economics & $\mathrm{x}$ & & $x$ & $x$ & $\mathrm{X}$ \\
\hline - Sorting of scrap & $\mathrm{X}$ & $\mathrm{X}$ & & $\mathrm{x}$ & \\
\hline Product quality and performance & & & $\mathrm{x}$ & $\mathrm{x}$ & $\mathrm{x}$ \\
\hline - Surface finish & & $x$ & & & \\
\hline - High load factor & & & & $\mathrm{X}$ & \\
\hline - Performance and lifetime & $\mathrm{x}$ & & & & \\
\hline - Easy to mount and maintain & $\mathrm{X}$ & & & & \\
\hline - Small and lightweight & $\mathrm{x}$ & & & & \\
\hline - Material strength & $\mathrm{x}$ & $\mathrm{x}$ & & $\mathrm{x}$ & $\mathrm{x}$ \\
\hline \multicolumn{6}{|l|}{ Environment } \\
\hline - Green energy & $\mathrm{x}$ & $\mathrm{x}$ & & & $\mathrm{x}$ \\
\hline - Energy-efficient production & $\mathrm{x}$ & $\mathrm{x}$ & $\mathrm{X}$ & $\mathrm{x}$ & $\mathrm{x}$ \\
\hline - Energy or environmental management system & $\mathrm{x}$ & $\mathrm{x}$ & & $\mathrm{x}$ & $\mathrm{x}$ \\
\hline - Energy audits, large companies & $\mathrm{x}$ & & $\mathrm{x}$ & $\mathrm{x}$ & \\
\hline - Burn exhaust gases & & & $\mathrm{x}$ & & \\
\hline - Exhaust emissions, trucks & $\mathrm{x}$ & & & $\mathrm{x}$ & \\
\hline
\end{tabular}

The surface finish was only discussed in the focus group for the balcony glazing system. One reason for this is that the aluminium is a visible part of the balcony glazing system. Demands on surface finish could be relevant for the furniture as well but was not mentioned during the focus group. Such demands would not be relevant for the heat exchanger, motor component, and chassis part, since these product parts are not visible parts of the final products.

As discussed in Section 3.2.3, the weight of the product is important for reducing the fuel demand of the vehicle and enabling a higher load factor of the vehicle, which was discussed in the heat exchanger, motor component, and chassis part focus groups.

Table 3 shows in which focus groups the different energy efficiency measures were discussed. As for the demands, even though an efficiency measure was not discussed in a certain focus group, it could still be relevant for that supply chain.

Table 3. The energy efficiency measures discussed in the different focus groups.

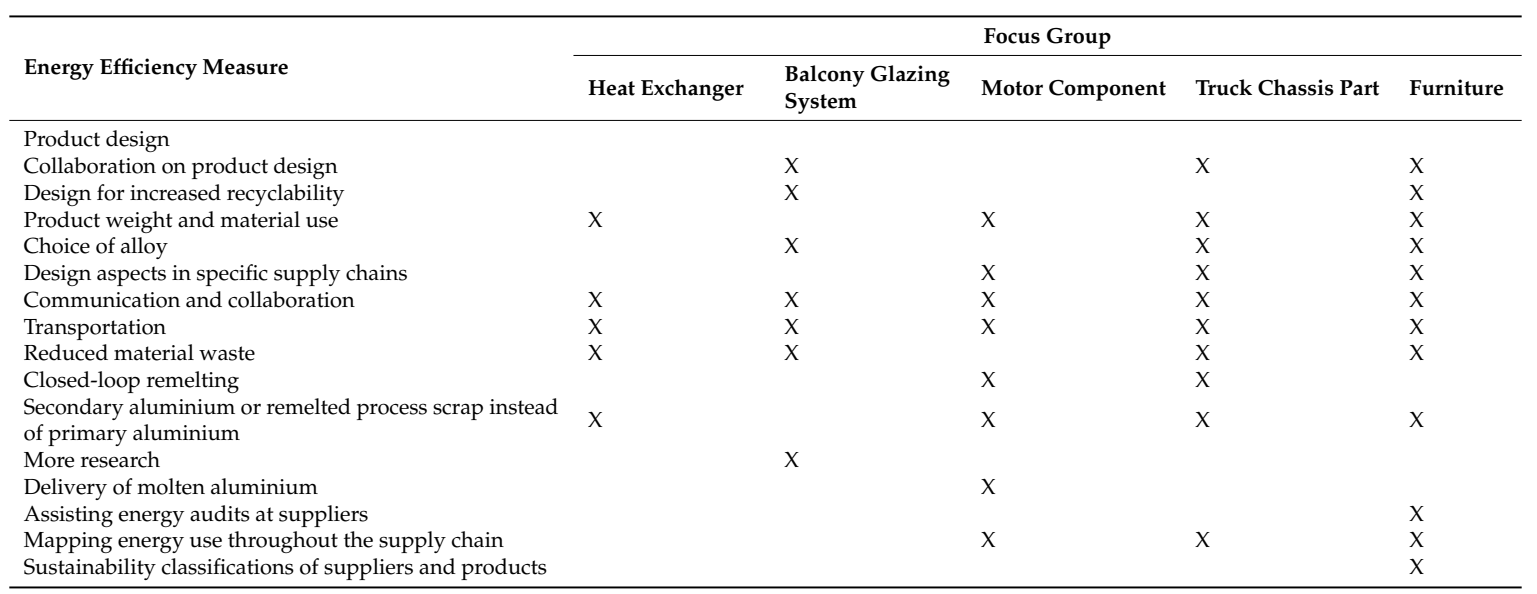

Product design, communication and collaboration, and transportation are areas for potential energy efficiency improvements that were discussed in all five focus groups. One reason for this is that these areas are general and applicable to all products.

Reducing material waste was discussed in all focus groups except the one for the motor component. This is despite the fact that shape casting has a lower material efficiency than other forming processes, e.g., rolling and extrusion [40]. One reason for this could be that it is more relevant to conduct the work 
with reduced material waste in a supply chain containing a foundry within each individual company. This is because there is not much that the companies in the supply chain can do together concerning reduced material waste. When there is a rolling mill or profile extruder instead, there is a greater possibility for the companies in the supply chain to work together to reduce material waste. This is because the material waste at a single company partly depends on the dimensions of the incoming semi-finished products.

The delivery of molten aluminium was only discussed in the motor component focus group. This is because delivering aluminium in molten form is only relevant when a foundry receives the metal, since foundries are the only type of processing plant that needs the metal in molten form.

The importance of using secondary aluminium or remelted process scrap instead of primary aluminium to reduce the supply chains' energy use was also raised in several focus groups. Using secondary aluminium or remelted process scrap would provide large energy savings in the production of the metal. The importance of designing products so that the different materials can be easily separated at the product's end-of-life was also raised in several focus groups. This would increase the amount of readily available aluminium scrap and could thus increase the use of secondary aluminium in new products.

\section{Discussion}

Tables 2 and 3 show that there are both similarities and differences between which demands and energy efficiency measures were discussed in the different focus groups. There are obvious reasons for some of these similarities and differences, which have been discussed previously in Section 3.14. Some other differences could be a consequence of the method used in this study. The focus groups were limited to two hours each and the respondents were free in their discussions. This means that potentially relevant areas (energy efficiency measures, demands, or energy efficiency potentials) could have been missed. One example is that the importance of the economic aspect was not discussed in the focus group for the balcony glazing system. The economic aspect is probably important for the balcony glazing system as well but was not touched upon in the focus group discussion, either because it was considered self-evident or because other areas were considered more important. The areas discussed in the different focus groups also depend on how the discussions evolved. As mentioned in Section 3.14, even though a demand or an efficiency measure was not discussed in a certain focus group, it could still be relevant for the particular supply chain.

Several demands were raised in the focus groups that could have direct or indirect effects on the energy use and the work with energy efficiency in the supply chains. The demands could sometimes counteract each other, e.g., as stated in Section 3.2.5, end-users have demands on a certain amount of horsepower for the car. This makes it harder to improve the energy efficiency of the car, which is also a common demand from the end-users. Furthermore, there can be demands that are more important to meet than improving energy efficiency, e.g., regarding product quality and economic feasibility. Thus, it could sometimes be hard to improve energy efficiency, both in the supply chains and in the products. Similar challenges were encountered by Roehrich et al. [18], who found that not all sustainability policies drive companies towards the same goal.

The economic aspect was shown to be an important driving force for the companies to improve their energy efficiency. However, demands from customers and the authorities provide an additional driving force for improved energy efficiency. This is in line with the statement from Walker and Phillips [20] that a wide range of socio-economic pressures may be needed to drive the companies to become "greener". Additionally, Centobelli et al. [17] highlight relational drivers (e.g., customer pressure) and regulation drivers (e.g., government support) as main drivers for the adoption of energy efficiency and environmental initiatives. Similarly, Roehrich et al. [18] found industrial competition, regulations, and the expectations of downstream buyers and customers to be the main drivers for the adoption of GSCM practices in the aerospace industry. They also found that while price, quality, and delivery are the most important factors in supplier selection, factors regarding, e.g., environmental 
management systems, greenhouse gas (GHG) emissions and hazardous materials are important in the selection of green suppliers. The ISO14001 certification could be an important tool for measuring how active suppliers regard environmental issues [18]. However, although an ISO14001 certificate is an indication that an environmental improvement process is adopted at the company, this process could look very different for different companies and industries [18]. Long-term cost savings or other benefits were found to be essential for motivating suppliers to participate in initiatives to improve the environmental performance of the supply chain [18]. Higher product costs, a lack of priority and clear directions from top management, a lack of unambiguous information, a perceived trade-off between sustainability and cost, and competing objectives are barriers to the procurement of green products [10].

Large retailers typically have more market power and act as leaders in a supply chain [41]. These retailers commonly demand environmentally friendly products from their suppliers, which is motivated by the increasing environmental awareness of end-users [41]. To increase their market share, suppliers are actively implementing environmental initiatives as a response to the demands from the retailer [41]. Environmental demands on suppliers have been raised by other authors as well, e.g., References $[8,10,13,18,24,42,43]$. The evaluation and auditing of suppliers, as well as visiting suppliers' sites, are important parts of a green purchasing strategy $[8,10,18]$. This is important for ensuring supplier compliance and for driving the joint work on environmental performance improvements [18]. Environmental information could be requested from the supplier during the procurement process to determine whether a supplier has basic elements of an environmental management system in place [13].

It could be worth reviewing the demands to see whether any of the demands could be changed. For example, unnecessarily high demands on surface finish for product parts that are not visible could lead to the unnecessary scrapping of metal that does not fulfil the demands. Another example is that the demands could perhaps be changed to allow for the use of recycled aluminium instead of primary aluminium. This would yield large energy savings (about 95\%) in the first part of the supply chain.

There are several measures that companies within supply chains can carry out together to improve the energy efficiency of the entire supply chain. Among the most important areas for potentially improved energy efficiency found in this study are: Product design, communication and collaboration, transportation, the use of secondary aluminium or remelted process scrap, and reduced material waste. The design phase provides the greatest possibility for affecting the energy efficiency of the product and its production, and lays the foundation for subsequent work with energy efficiency. The product design has also been raised in previous research as important factors for reduced use of energy and other resources as well as reduced environmental impact; see for example Reference [6-10,12,14,17-19,24-26,31,44-50]. In the design phase, a life cycle perspective, including the manufacturing phase (e.g., production processes, packaging, transportation, and storage), the use phase and end-of-life handling is important [14,18,24,26,44,49]. More resources might be needed in one part of the life cycle to reduce the environmental impact of the entire life cycle [18]. For product design, involving suppliers at an early stage is important $[18,46]$. Similar to our results, Roehrich et al. [18] found that aircraft manufacturers and airlines demand products with weights that are as low as possible to save fuel in the vehicles' use phase.

Discussing energy issues explicitly in the communication and collaboration between companies is important for improving energy efficiency. Large energy savings can be achieved by using secondary or remelted aluminium instead of primary aluminium, and thus it is important to work together to increase the use of secondary or remelted aluminium. The collaboration between the companies in the supply chain has also been raised as an important issue in previous research, e.g., collaboration in general $[6,7,13,16,18,19,21,24,43]$ or in regard to transportation $[28,42]$, cleaner production $[8,16,41]$, product design $[8,10,17,41]$, environmental/sustainability goals $[8,17]$, returnable packaging, energy-and eco-efficient products in use [8], financial investments [6,41,51], mapping of GHG emissions, environmental training and education [13], circular economy [31,50], management [6] 
and research and development [41]. Collaboration provides an opportunity for overcoming the barriers to energy efficiency [6]. Increased transparency between the companies in the supply chain is needed for successful collaboration [10]. Additionally, building up the level of trust with suppliers is important for improving sustainability [21].

A first step in the joint work with energy efficiency could be to conduct an energy audit for the entire supply chain. This would provide some understanding of the energy use throughout the supply chain and a basis for discussions on where the greatest efforts for improved energy efficiency should be directed. The results from mapping the supply chain could be used for reducing the costs of energy use, manufacturing and packaging, and as support during the design phase [13]. They could also identify the most energy demanding parts of the supply chain and the most influential parameters and decision-making steps, which would provide information for assessing the energy saving potential [6,7]. Similarly, life cycle assessments can be used for measuring and managing the environmental impact and for achieving the largest saving in environmental impact [6].

The transportation of goods between the companies could be handled by one of the companies or outsourced to an external party. Either way, it is important that the logistics and load factor are optimised. Obviously, reduced material weight also reduces energy use. Previous research has highlighted transportation as an important area for reduced energy use and environmental impact in supply chains; see, for example, Reference $[6,7,9,10,14,17,18,20,22,24,25,27-30,42,45-48,52,53]$. Several aspects are addressed in previous research that could affect the energy use and environmental impact from transportation. Examples of such aspects are the distance travelled, direct flows of goods, transportation mode, load factor/capacity, filling degree, payload ratio, coordination of transportation, and warehousing strategy. Other examples include redesigning the product shape and packaging, reducing product volume and weight, and decisions on sourcing. These examples are also found in the results of this article.

The use of secondary aluminium or remelted process scrap was emphasised as being important for reducing the energy use. The design is important for increasing the recyclability of the product. It was mentioned that designing the product so that it could easily be disassembled and thus make it easy to separate the different materials is beneficial for increasing the production of secondary aluminium. Disassembly has been raised in previous research as an important aspect for increasing the product's recyclability and remanufacturability; see for example $[6,8,9,19,24,26,31,44,46,48]$. The involvement of different industries along the supply chain in designing products suitable for recycling is needed for successful recycling [54].

Closed-loop remelting of process scrap was cited as being beneficial from an energy perspective. The closed-loop strategy, in which scrap is remelted into the same alloy, can effectively avoid the need for dilution of impurities and addition of alloying elements [55]. This results in a minimal environmental impact per produced tonne of metal, where the energy use for the remelting process itself and the material losses constitute the majority of the environmental impact [55]. There is also an economic benefit, e.g., from a reduced need for primary aluminium for dilution and from avoiding the reduced product value occurring when down-cycling the alloy [55]. This strategy is easier to implement for single alloys with high volume scrap streams and where the demand is high [55]. If the scrap is sent back to a supplier, the transportation distance needs to be short enough to promote the remelting from a cost and time perspective [32]. Additionally, a short transportation distance results in lower environmental impact from transportation [32] and thus potentially retains a share of the environmental benefit from closed-loop remelting. Previous research has referred to closed-loop remanufacturing/supply chains where used or end-of-life products are taken back by the companies to be recovered, repaired, refurbished, remanufactured, and reused with the aim of reselling the products or recycling them into new products of similar alloy; see, for example, Reference $[9,23,31,45,55-58]$. The related concepts of circular economy and reverse logistics have also been raised in previous research; see, for example, Reference [7-9,12,14,17,19,25,31,42,50]. The closed-loop remelting of process 
scrap is a subconcept of the more general concepts of a closed-loop supply chain, circular economy, and reverse logistics.

It is obviously better from an energy perspective to reduce the amount of process scrap arising in the supply chains than to send it for remelting. Yield improvements leading to savings in liquid metal demand could lead to significant savings in energy use and GHG emissions, since liquid metal production is typically the most energy- and GHG-intensive process along the supply chain [34]. Yield improvements are commonly driven by savings in material cost, rather than savings in energy or $\mathrm{CO}_{2}$ emissions [34]. Designing components with geometries more similar to those of semi-finished products, the development of new production processes with higher yields, and operating existing processes more effectively are the main strategies for reducing yield losses [34]. The range of geometries for semi-finished products are typically limited to allow for the use of economy of scale in the production processes and for maximising versatility [34]. The final components are diverse and often complex, and significant amounts of scrap could occur when converting the semi-finished products into the final components [34]. Yield losses could be reduced by adapting the geometries of the semi-finished products to the customer-specific needs, which is often limited within the boundaries of the specific site [34]. In blanking, reduced yield losses could be achieved by fitting several components from different customers together in a way to reduce material waste as much as possible, which could be facilitated by a modified component design [34]. Significant improvements in material yield require an integrated approach for measuring and improving the yield along the entire supply chain [34]. Each company needs to have a complete knowledge of both their planned and unplanned yield before collaboration along the supply chain can take place [34].

The possibility of delivering aluminium in molten form was discussed in the focus group for the motor component. Ferretti et al. [33] showed that the delivery of molten aluminium provides both economic and environmental benefits, compared to the delivery of solid ingots. These benefits include energy savings due to the elimination of remelting at the foundry and storage cost savings [33]. Delivery of molten aluminium entails a strong partnership between the two supply chain actors, which is based on technical and managerial factors rather than price [33]. The adoption of the delivery method may be slowed by two key constraints [33]. The first is that it is not suitable for transportation further than $200-250 \mathrm{~km}$ [33]. The other is that the receiver of the molten metal needs a special overhead bridge crane to facilitate the work and for safety reasons [33].

The furniture producer has a sustainability classification system for their suppliers and products, with goals and indicators. Such a type of sustainability accounting is needed for assessing a potential solution's sustainability impact and thus to make progress towards improved sustainability [59]. It is worth thinking about who the recipients of the results from the sustainability accounting are; whether they are internal or external actors [59]. The use of environmental goals is a way of addressing the environmental impact of supply chains [7]. The suppliers should be involved in meeting the goals [8]. Environmental indicators are a way of measuring the environmental performance of the entire supply chain [45] and can be used when setting goals [13]. The management of environmental/sustainability performance utilises indicators as an important tool [7,24,59]. Indicators can be used for establishing baselines, identifying trends, and evaluating different options [59]. The performance aspects to be improved and the direction of change should be shown by the indicators [19].

Even though the largest potential for energy efficiency improvements appears to be within each individual company, the measures that the companies can carry out together would have great potentials to further improve the energy efficiency of the entire supply chains. Of course, the overall potential depends to some extent on the type of production processes the companies have, e.g., the balcony glazing system producer believed that there was not much left to be done within their company from an energy efficiency perspective.

The aim of this paper was to study how the companies in the aluminium industry's supply chains can work together to improve the energy efficiency of the entire supply chains, which is a relatively unexplored research area. Several energy efficiency measures and areas for potentially improved 
energy efficiency were found. The paper thus makes a contribution to how the companies can work together on energy efficiency and to what measures or areas for improved energy efficiency that are applicable to the aluminium industry. Demands put on the companies and products are important to acknowledge since they may have an impact on the degree of implementation of energy efficiency measures. Some demands can act as drivers for improved energy efficiency, e.g., the economic aspect and demands from customers and authorities on energy efficiency or reduced environmental impact. On the other side, some demands can act as barriers to improved energy efficiency, e.g., demands on material strength and surface finish. The investigation of what demands that are put on the companies and products could provide a basis for how to deal with these demands and thus to facilitate improvements in energy efficiency.

Only five case objects were studied in the article. It is thus hard to generalise the findings from this study to the entire aluminium industry. However, clear links between the findings in this article and the findings in previous studies within GSCM and SSCM have been identified. Many energy efficiency measures found in this study touch upon general areas within supply chains and SCM, e.g., product design, transportation, and waste management. This implies that the findings may be more widely applicable than for the cases studied.

In future studies, it would be interesting to study specific aspects of supply chains and SCM, e.g., procurement and collaboration, with a focus on energy efficiency in the supply chains of the aluminium industry. Other aspects of environmental and sustainability improvements in supply chains and SCM could also be studied. This article concluded that demands exist that are more important to meet than improving energy efficiency, e.g., regarding product quality and economic feasibility. It would be interesting to study the consumers' perception of energy efficiency in the supply chains. For example, are the consumers willing to accept a lower quality or to pay a higher product price if this facilitate improved energy efficiency in the supply chains and the products?

\section{Conclusions}

The aim of this paper was to study how the companies in the aluminium industry's supply chains can work together to improve the energy efficiency of the entire supply chains and which demands that negatively or positively affect how the companies' work with improving energy efficiency.

Despite the fact that the companies can save money through energy efficiency, energy efficiency measures are sometimes not implemented. Environmental demands from customers and the authorities would provide the additional incentives needed for companies to work harder to improve energy efficiency. However, other prioritised demands, such as material strength, can be a barrier to improving energy efficiency. Therefore, it could be worth reviewing these demands to see whether any of them could be changed, thus facilitating the work to improve energy efficiency.

Several measures that companies within supply chains can conduct together to improve the energy efficiency of the entire supply chain were found. Among the most important areas for potentially improved energy efficiency found in this study are: Product design, communication and collaboration, transportation, the use of secondary aluminium or remelted process scrap, and reduced material waste.

The measures found in this study would have great potential to improve the energy efficiency of the entire supply chains, although the greatest potential for energy efficiency improvements appears to be within each individual company. The respondents argued that the complexity of the supply chains made it hard to estimate how large the energy efficiency potentials were.

It is hard to generalise the results and conclusions from five cases to an entire industry, but these results may be valid more widely than just for the cases studied. However, there is potential for further research within the area of the aluminium industry and its supply chains.

Author Contributions: J.H. and M.T.J. cooperatively designed and conducted the focus groups. J.H. transcribed, coded, and analysed the focus group discussions. J.H. and M.T.J. wrote the paper jointly, although J.H. provided a first draft summary of each focus group separately. M.T.J. did funding acquisition and project administration. M.T.J. supervised the work. 
Funding: This research was financed by the Swedish Energy Agency, project number 40552-1. The APC was funded by the Linköping University Library.

Acknowledgments: We would like to thank the respondents from the companies who participated in the focus groups for their time and the valuable information they provided before, during, and after the focus groups. We appreciate the valuable information received from the Swedish Aluminium Association. We would like to thank Magnus Karlsson at the Division of Energy Systems at Linköping University for his valuable comments on the draft article.

Conflicts of Interest: The authors declare no conflict of interest. The founding sponsor had no role in the design of the study; in the collection, analyses, or interpretation of data; in the writing of the manuscript, or in the decision to publish the results.

\section{References}

1. World Commission on Environment and Development. Our Common Future; Oxford University Press: Oxford, UK, 1987.

2. Adams, W.M. The Future of Sustainability: Re-Thinking Environment and Development in the Twenty-First Century; The World Conservation Union: Gland, Switzerland, 2006.

3. Elkington, J. Cannibals with Forks: The Triple Bottom Line of 21st Century Business, Paperback ed.; Capstone Publishing Ltd.: Oxford, UK, 1999.

4. Savitz, A.W.; Weber, K. The Triple Bottom Line: How Today's Best-Run Companies Are Achieving Economic, Social, and Environmental Success-and How You Can Too, 2nd ed.; Jossey-Bass: San Francisco, CA, USA, 2014.

5. Goetschalckx, M. Supply Chain Engineering; Springer Science \& Business Media: New York, NY, USA, 2011.

6. Marchi, B.; Zanoni, S. Supply chain management for improved energy efficiency: Review and opportunities. Energies 2017, 10, 1618. [CrossRef]

7. Kalenoja, H.; Kallionpää, E.; Rantala, J. Indicators of energy efficiency of supply chains. Int. J. Logist. Res. Appl. 2011, 14, 77-95. [CrossRef]

8. De Sousa Jabbour, A.B.L.; Verdério Júnior, S.A.; Jabbour, C.J.C.; Leal Filho, W.; Campos, L.S.; De Castro, R. Toward greener supply chains: Is there a role for the new ISO 50001 approach to energy and carbon management? Energy Effic. 2017, 10, 777-785. [CrossRef]

9. Carter, C.R.; Rogers, D.S. A framework of sustainable supply chain management: Moving toward new theory. Int. J. Phys. Distrib. Logist. Manag. 2008, 38, 360-387. [CrossRef]

10. Preuss, L. Addressing sustainable development through public procurement: The case of local government. Supply Chain Manag. Int. J. 2009, 14, 213-223. [CrossRef]

11. Zanoni, S.; Bettoni, L.; Glock, C.H. Energy implications in the single-vendor single-buyer integrated production inventory model. In Proceedings of the IFIP Advances in Information and Communication Technology, Rhodes, Greece, 30 September-2 October 2013; Volume 397, pp. 57-64.

12. El Saadany, A.M.A.; Jaber, M.Y.; Bonney, M. Environmental performance measures for supply chains. Manag. Res. Rev. 2011, 34, 1202-1221. [CrossRef]

13. Lee, K.H.; Cheong, I.M. Measuring a carbon footprint and environmental practice: The case of Hyundai Motors Co. (HMC). Ind. Manag. Data Syst. 2011, 111, 961-978. [CrossRef]

14. Ji, G.; Gunasekaran, A.; Yang, G. Constructing sustainable supply chain under double environmental medium regulations. Int. J. Prod. Econ. 2014, 147, 211-219. [CrossRef]

15. Zhang, Q.; Shah, N.; Wassick, J.; Helling, R.; van Egerschot, P. Sustainable supply chain optimisation: An industrial case study. Comput. Ind. Eng. 2014, 74, 68-83. [CrossRef]

16. Xie, G. Cooperative strategies for sustainability in a decentralized supply chain with competing suppliers. J. Clean. Prod. 2016, 113, 807-821. [CrossRef]

17. Centobelli, P.; Cerchione, R.; Esposito, E. Environmental sustainability and energy-efficient supply chain management: A review of research trends and proposed guidelines. Energies 2018, 11, 275. [CrossRef]

18. Roehrich, J.K.; Hoejmose, S.U.; Overland, V. Driving green supply chain management performance through supplier selection and value internalisation: A self-determination theory perspective. Int. J. Oper. Prod. Manag. 2017, 37, 489-509. [CrossRef]

19. Faisal, M.N. Sustainable supply chains: A study of interaction among the enablers. Bus. Process Manag. J. 2010, 16, 508-529. [CrossRef] 
20. Walker, H.; Phillips, W. Sustainable procurement: Emerging issues. Int. J. Procure. Manag. 2009, 2, 41-61. [CrossRef]

21. Walker, H.; Preuss, L. Fostering sustainability through sourcing from small businesses: Public sector perspectives. J. Clean. Prod. 2008, 16, 1600-1609. [CrossRef]

22. Farahani, N.Z.; Noble, J.S.; Klein, C.M.; Enayati, M. A decision support tool for energy efficient synchromodal supply chains. J. Clean. Prod. 2018, 186, 682-702. [CrossRef]

23. Kadambala, D.K.; Subramanian, N.; Tiwari, M.K.; Abdulrahman, M.; Liu, C. Closed loop supply chain networks: Designs for energy and time value efficiency. Int. J. Prod. Econ. 2017, 183, 382-393. [CrossRef]

24. Tsoulfas, G.T.; Pappis, C.P. A model for supply chains environmental performance analysis and decision making. J. Clean. Prod. 2008, 16, 1647-1657. [CrossRef]

25. Srivastava, S.K. Green supply-chain management: A state-of-the-art literature review. Int. J. Manag. Rev. 2007, 9, 53-80. [CrossRef]

26. Jawahir, I.; Rouch, K.E.; Dillon, O.; Holloway, L.; Hall, A. Design for sustainability (DFS): New challenges in developing and implementing a curriculum for next generation design and manufacturing engineers. Int. J. Eng. Educ. 2007, 23, 1053-1064.

27. Duflou, J.R.; Sutherland, J.W.; Dornfeld, D.; Herrmann, C.; Jeswiet, J.; Kara, S.; Hauschild, M.; Kellens, K. Towards energy and resource efficient manufacturing: A processes and systems approach. CIRP Ann. Manuf. Technol. 2012, 61, 587-609. [CrossRef]

28. Ala-Harja, H.; Helo, P. Green supply chain decisions-Case-based performance analysis from the food industry. Transp. Res. Part E Logist. Transp. Rev. 2014, 69, 97-107. [CrossRef]

29. Rizet, C.; Browne, M.; Cornelis, E.; Leonardi, J. Assessing carbon footprint and energy efficiency in competing supply chains: Review-Case studies and benchmarking. Transp. Res. Part D Transp. Environ. 2012, 17, 293-300. [CrossRef]

30. Berlin, J.; Sonesson, U.; Tillman, A.M. Product chain actors $\backslash$ potential for greening the product life cycle: The case of the swedish postfarm milk chain. J. Ind. Ecol. 2008, 12, 95-110. [CrossRef]

31. Leising, E.; Quist, J.; Bocken, N. Circular economy in the building sector: Three cases and a collaboration tool. J. Clean. Prod. 2018, 176, 976-989. [CrossRef]

32. Khoo, H.H.; Spedding, T.A.; Bainbridge, I.; Taplin, D.M.R. Creating a green supply chain. Green. Manag. Int. 2001, 35, 71-88. [CrossRef]

33. Ferretti, I.; Zanoni, S.; Zavanella, L.; Diana, A. Greening the aluminium supply chain. Int. J. Prod. Econ. 2007, 108, 236-245. [CrossRef]

34. Milford, R.L.; Allwood, J.M.; Cullen, J.M. Assessing the potential of yield improvements, through process scrap reduction, for energy and $\mathrm{CO}_{2}$ abatement in the steel and aluminium sectors. Resour. Conserv. Recycl. 2011, 55, 1185-1195. [CrossRef]

35. Haraldsson, J.; Johansson, M.T. Review of measures for improved energy efficiency in production-related processes in the aluminium industry-From electrolysis to recycling. Renew. Sustain. Energy Rev. 2018, 93, 525-548. [CrossRef]

36. Wibeck, V. Fokusgrupper: Om Fokuserade Gruppintervjuer som Undersökningsmetod [Focus Groups: On Focused Group Interviews as Research Method], 2nd ed.; Studentlitteratur AB: Lund, Sweden, 2010.

37. Saldaña, J. The Coding Manual for Qualitative Researchers, 2nd ed.; SAGE Publications: London, UK; Thousand Oaks, CA, USA, 2013.

38. Rabiee, F. Focus-group interview and data analysis. Proc. Nutr. Soc. 2004, 63, 655-660. [CrossRef]

39. Krueger, R.A.; Casey, M.A. Focus Groups: A Practical Guide for Applied Research; Sage Publications, Cop.: Thousand Oaks, CA, USA, 2009.

40. Cullen, J.M.; Allwood, J.M. Mapping the global flow of aluminum: From liquid aluminum to end-use goods. Environ. Sci. Technol. 2013, 47, 3057-3064. [CrossRef] [PubMed]

41. Zhang, Q.; Tang, W.; Zhang, J. Who should determine energy efficiency level in a green cost-sharing supply chain with learning effect? Comput. Ind. Eng. 2018, 115, 226-239. [CrossRef]

42. Evangelista, P.; Santoro, L.; Thomas, A. Environmental sustainability in third-party logistics service providers: A systematic literature review from 2000-2016. Sustainability 2018, 10, 1627. [CrossRef]

43. Torres-Ruiz, A.; Ravindran, A.R. Multiple criteria framework for the sustainability risk assessment of a supplier portfolio. J. Clean. Prod. 2018, 172, 4478-4493. [CrossRef] 
44. Yan, J.; Feng, C. Sustainable design-oriented product modularity combined with 6r concept: A case study of rotor laboratory bench. Clean Technol. Environ. Policy 2014, 16, 95-109. [CrossRef]

45. Rao, P.H. Measuring environmental performance across a green supply chain: A managerial overview of environmental indicators. Vikalpa 2014, 39, 57-74. [CrossRef]

46. Alblas, A.A.; Peters, K.; Wortmann, H. Process alignment for sustainable product development: The essential role of supplier and customer involvement processes. In IFIP International Conference on Advances in Information and Communication Technology; Springer: Berlin/Heidelberg, Germany, 2013; Volume 415, pp. 556-567.

47. Vlotman, W.F.; Ballard, C. Water, food and energy supply chains for a green economy. Irrig. Drain. 2014, 63, 232-240. [CrossRef]

48. Carter, C.R.; Easton, P.L. Sustainable supply chain management: Evolution and future directions. Int. J. Phys. Distrib. Logist. Manag. 2011, 41, 46-62. [CrossRef]

49. Rünger, G.; Schubert, A.; Goller, S.; Krellner, B.; Steger, D. Integrating energy-saving process chains and product data models. In Glocalized Solutions for Sustainability in Manufacturing. In Proceedings of the 18th CIRP International Conference on Life Cycle Engineering, Braunschweig, Germany, 2-4 May 2011; pp. 519-524.

50. Husgafvel, R.; Linkosalmi, L.; Dahl, O. Company perspectives on the development of the CE in the seafaring sector and the Kainuu region in Finland. J. Clean. Prod. 2018, 186, 673-681. [CrossRef]

51. Marchi, B.; Zanoni, S.; Ferretti, I.; Zavanella, L.E. Stimulating investments in energy efficiency through supply chain integration. Energies 2018, 11, 858. [CrossRef]

52. Zhou, Z.; Yao, B.; Xu, W.; Wang, L. Condition monitoring towards energy-efficient manufacturing: A review. Int. J. Adv. Manuf. Technol. 2017, 91, 3395-3415. [CrossRef]

53. Stuchtey, M.; Meyer, T. Energy-efficient supply chains: Big savings within our grasp. Int. Commer. Rev. 2010, 8, 136-144. [CrossRef]

54. Golev, A.; Scott, M.; Erskine, P.D.; Ali, S.H.; Ballantyne, G.R. Rare earths supply chains: Current status, constraints and opportunities. Resour. Policy 2014, 41, 52-59. [CrossRef]

55. Paraskevas, D.; Kellens, K.; Dewulf, W.; Duflou, J.R. Environmental modelling of aluminium recycling: A life cycle assessment tool for sustainable metal management. J. Clean. Prod. 2015, 105, 357-370. [CrossRef]

56. Kartalis, C.N.; Papaspyrides, C.D.; Pfaendner, R.; Hoffmann, K.; Herbst, H. Closed loop recycling of bottle crates using the restabilization technique. Macromol. Mater. Eng. 2003, 288, 124-136. [CrossRef]

57. Kartalis, C.N.; Papaspyrides, C.D.; Pfaendner, R. Closed-loop recycling of postused pp-filled garden chairs using the restabilization technique. Iii. Influence of artificial weathering. J. Appl. Polym. Sci. 2003, 89, 1311-1318. [CrossRef]

58. Pauliuk, S.; Kondo, Y.; Nakamura, S.; Nakajima, K. Regional distribution and losses of end-of-life steel throughout multiple product life cycles-Insights from the global multiregional matrace model. Resour. Conserv. Recycl. 2017, 116, 84-93. [CrossRef]

59. Burritt, R.L.; Schaltegger, S. Measuring the (un-)sustainability of industrial biomass production and use. Sustain. Account. Manag. Policy J. 2012, 3, 109-133. [CrossRef]

(C) 2019 by the authors. Licensee MDPI, Basel, Switzerland. This article is an open access article distributed under the terms and conditions of the Creative Commons Attribution (CC BY) license (http://creativecommons.org/licenses/by/4.0/). 